\title{
CARBON MATERIALS PREPARED FROM CIGARETTE FILTERS APPLIED FOR CLOFIBRIC ACID ADORPTION
}

\author{
${ }^{1}$ Susana C. R. MARQUES, ${ }^{1}$ Jan FILIP \\ ${ }^{1}$ Regional Centre of Advanced Technologies and Materials, Palacký University in Olomouc, \\ Czech Republic, EU, susanacristina.roquemarques@upol.cz
}

https://doi.org/10.37904/nanocon.2020.3733

\begin{abstract}
Chars and carbon membranes were prepared from fresh and smoked cigarette filters, and used as adsorbents for clofibric acid removal. Carbonization of cigarette filters took place at 650,750 and $900{ }^{\circ} \mathrm{C}$, whereas membranes were synthesized by filter dissolution in acetone, using $\mathrm{NaCl}$ (porogen) and glycerol (plasticizer). Acid mediated carbonization ( 225 and $250^{\circ} \mathrm{C}$ ) of the membranes was performed. Solution $\mathrm{pH}$ was monitored throughout the adsorption experiments. The chars are basic powders with apparent surface areas up to $494 \mathrm{~m}^{2} \mathrm{~g}^{-1}$ and a porosity composed by supermicropores (0.7-2 nm wide) and mesopores (2-50 nm wide), allowing clofibric acid (critical dimension $0.6 \mathrm{~nm}$ ) to access all adsorption sites. Carbonization of smoked filters promoted higher porosity levels and SEM analysis showed that a more extensive carbonization occurred in the outer surface of the chars particles. The presence of $\mathrm{TiO}_{2}$ particles was confirmed in all the chars. Pores were homogeneously created at the membranes surface. Acidic carbon membranes ( $\mathrm{pH}_{\mathrm{pzc}} \approx 3.7$ ) were obtained with different degrees of porosity, proportional to the pyrolysis temperature. Both forms of clofibric acid (protonated and deprotonated) were readily adsorbed onto the carbon materials, with exception of the chars prepared at $900{ }^{\circ} \mathrm{C}$, which adsorbed predominantly the deprotonated form. In equilibrium, an inverse correlation between solution $\mathrm{pH}$ and concentration of the pollutant was observed, and higher uptakes were observed for experiments with solution $\mathrm{pH}$ values above 5 , suggesting that adsorption of the neutral species contributed significantly to the overall removal.
\end{abstract}

Keywords: Cigarette filters, chars, carbon membranes, adsorption, clofibric acid

\section{INTRODUCTION}

Cigarette butts (CBs) are among the most prevalent sources of waste litter worldwide [1]. Littered CBs have been found in ecosystems, such as urban areas, beaches and even in the aquatic system, where their presence raises a great level of concern [2]. The main source of contamination in CBs is the cigarette filter (CF), consisting in more than 15000 non-biodegradable cellulose acetate fibers subjected to titanium dioxide (a delustrant), and packed firmly together with triacetin (a binding agent), to produce a single filter. During smoking, a complex mixture of chemical compounds, including toxic heavy metals, polycyclic aromatic hydrocarbons, pesticides, $\mathrm{N}$-nitrosamines and nicotine, is trapped in the CFs [2]. When CBs are littered, these contaminants may leach into the terrestrial and aquatic environments, posing a serious health hazard to humans, animals and even vegetation [2]. CFs have been used, in recent years, as cellulose derivative sources for the development of carbon materials but many questions are still to be answered [3-5]. In this study, chars and carbon membranes were prepared from CFs, and their texture, chemistry and morphology characterized. The materials were applied for clofibric acid adsorption, and the role of solution $\mathrm{pH}$ change in the adsorption mechanism was investigated under equilibrium conditions. 


\section{MATERIALS AND METHODS}

\subsection{Materials preparation}

Fresh (UF) and smoked filters (SF) were carbonized, at 650,750 and $900{ }^{\circ} \mathrm{C}$ for $2 \mathrm{~h}\left(\mathrm{~N}_{2}\right.$ flow $15 \mathrm{~cm}^{3} \mathrm{~s}^{-1}$, heating rate $5{ }^{\circ} \mathrm{C} \mathrm{min}^{-1}$ ), in a tube furnace (model LT 50/300/13). Prior to pyrolysis, the filters were cut into cylinders approximately $0.5 \mathrm{~cm}$ thick to increase the surface area exposed to thermal treatment (labelled as UC and SC - fresh and smoked cut filters, respectively). The chars were named according to filter type and carbonization temperature, for example, Ch_UC650.

Membranes were synthesized by dissolving $2 \mathrm{~g}$ of filters in approximately $10 \mathrm{~cm}^{3}$ of acetone (purity $\geq 99 \%$, Sigma-Aldrich) under stirring. Grounded $\mathrm{NaCl}$ (weight ratio of $\mathrm{NaCl}$ :filters of 1:7) was used as porogen, and glycerol $\left(3 \mathrm{~cm}^{3}\right.$, Lach-ner) was added. The mixture was poured onto a petri dish for solvent evaporation, at room temperature. After solidification, the membranes were washed with distilled water, at $80{ }^{\circ} \mathrm{C}$. The membranes were designated according to type of filters (UF or SF) used, for example Memb_SF. Acid mediated carbonization was carried out by soaking the membranes in $50 \mathrm{~cm}^{3}$ of phosphoric acid (UF soaked in $0.5 \mathrm{~mol} \mathrm{dm}^{-3}$ and for SF $1 \mathrm{~mol} \mathrm{dm}^{-3}$ was used) for $2 \mathrm{~h}$, prior to pyrolysis. Carbonization took place at 225 and $250{ }^{\circ} \mathrm{C}$, for $1 \mathrm{~h}\left(\mathrm{~N}_{2}\right.$ flow $15 \mathrm{~cm}^{3} \mathrm{~s}^{-1}$, heating rate $\left.5^{\circ} \mathrm{C} \mathrm{min}{ }^{-1}\right)$. The designation of the carbon membranes included type of filter, temperature of carbonization and acid (p) used, for example, Memb_SF250p.

\subsection{Characterization of samples}

$\mathrm{N}_{2}$ adsorption-desorption, was carried out in a volumetric gas adsorption analyzer (3Flex, Micromeritics), at $-196{ }^{\circ} \mathrm{C}$. The samples were degassed prior to pyrolysis, under vacuum $(0.07 \mathrm{mbar})$ for 12 hours at $130{ }^{\circ} \mathrm{C}$, and high purity $(99.999 \%) \mathrm{N}_{2}$ and He gases were used for the measurements. The apparent surface area, $A_{\mathrm{BET}}$, was calculated according to recommendations in norm ISO 9277, and the microporosity of the samples was analyzed by applying the $\alpha_{\mathrm{s}}$ method [6,7]. This method allowed the determination of the total micropore volume, $V_{\text {micro, }}$ and the specific volumes of ultra, $V_{\text {ultra, }}$ and supermicropores, $V_{\text {super. }}$

Scanning Electron Microscopy (SEM) was employed using a field emission gun scanning electron microscope (Hitachi SU6600) with an X-ray energy dispersive system (EDS) (accelerating voltage of $1.0 \mathrm{kV}$ ). EDS spectra were acquired using a Thermo Noran System 7 (Thermo Scientific, USA) with Si(Li) detector (accelerating voltage of $15 \mathrm{kV}$ and acquisition time of $300 \mathrm{~s}$ ).

The $\mathrm{pH}$ at the point of zero charge ( $\mathrm{pH}$ Pzc) was determined using $5 \mathrm{~cm}^{3}$ of $\mathrm{NaCl}$ solutions $\left(0.1 \mathrm{~mol} \mathrm{dm}^{-3}\right)$, with initial $\mathrm{pH}$ values around 2, 4, 6, 8 and 10, adjusted with sodium hydroxide and hydrochloric acid. Amounts of $20 \mathrm{mg}$ of char and $30 \mathrm{mg}$ of membrane were used. The solution $\mathrm{pH}$ values obtained after $24 \mathrm{~h}$ stirring were measured with a pH/ORP meter (Hanna Instruments, model HI 2211) equipped with a WTW electrode (model SenTix Mic).

X-ray powder diffraction (XRD) patterns were recorded using a PANalytical X'Pert PRO MPD diffractometer (PANalytical, The Netherlands), equipped with an X'Celerator detector and programmable divergence slit and diffracted beam anti-scatter slit. The data was collected using Co-Ka radiation ( $40 \mathrm{kV}, 30 \mathrm{~mA}, \lambda=0.1789 \mathrm{~nm})$, and undesirable $\mathrm{K} \beta$ radiation was filtered using an iron filter. Measurements were made in a Bragg-Brentano geometry (angular range $2 \theta: 5^{\circ}-105^{\circ}$, and step size of $0.033^{\circ}$ ). High Score Plus software (PANalytical), with PDF-4+ database, was used for the identification of the crystalline phases.

\subsection{Liquid phase adsorption}

Clofibric acid ( $\mathrm{TCl}$ Chemicals, purity $>97.0 \%$ ) adsorption from aqueous solutions was carried out at the dissolution $\mathrm{pH}$ and room temperature. The materials $(5 \mathrm{mg}$ of char, $10 \mathrm{mg}$ of membrane) were immersed in $5 \mathrm{~cm}^{3}$ of solution. Equilibrium adsorption studies were performed by adding $10 \mathrm{mg}$ of chars and $20 \mathrm{mg}$ of membrane to pollutant solutions (initial concentrations ranged from 5 to $200 \mathrm{mg} \mathrm{dm}^{3}$ ) in glass vials ( $30 \mathrm{rpm}$, 
Multi Bio RS-24 programmable rotator). Individual suspensions were prepared and, after equilibrium contact time, the concentration of the filtrated solution $\left(C_{\mathrm{e}}\right)$ was determined by UV/Visible spectrophotometry (Biochrom WPA Lightwave II), at wavelength of $280 \mathrm{~nm}$, and the corresponding uptake calculated $\left(q_{\mathrm{e}}\right)[8]$.

\section{RESULTS AND DISCUSSION}

\subsection{Chars}

The chars are basic powders and have developed wide porosities, composed exclusively by supermicropores and mesopores (Table 1). A more significant pore development was achieved at $650{ }^{\circ} \mathrm{C}$, for both fresh and smoked filters. The increase in carbonization temperature had less impact in the porosity of SC-chars, suggesting that the chemical compounds entrapped in the smoked filters prevented the excessive consumption of the fibers matrix while, at the same time, allowing for porosity development. A possible explanation for this is that the pyrolysis of cellulosic fibers leads to the release of water vapor and carbon dioxide, which are commonly used as activating agents in the synthesis of porous materials [9]. Then, tars entrapped in the filters may react with carbon dioxide, forming carbon monoxide and hydrogen [10]. Low yield values between 11 and $17 \%$ were obtained; it can be justified by the high thermal degradability of cellulose acetate, which decomposition onset has been reported to occur at $230{ }^{\circ} \mathrm{C}$ leading to a percentage of residue around $13 \%$ [11]. The slightly higher yields obtained for the smoked filters can be easily explained by the incomplete cracking of tars during carbonization.

Table 1 Textural properties, carbonization yields and $\mathrm{pH}$ pzc values of the chars. Carbonization yield defined as weight in $\mathrm{g}$ of char per $1 \mathrm{~g}$ of filters, $V_{\text {total }}$ corresponds to the nitrogen volume adsorbed at relative pressure of $0.95, V_{\text {meso }}=V_{\text {total }}-V_{\text {micro. }}$.

\begin{tabular}{|c|c|c|c|c|c|c|c|c|}
\hline Chars & Yield & $\begin{array}{c}\boldsymbol{A}_{\text {BET }}\left(\mathbf{m}^{2}\right. \\
\left.\mathbf{g}^{-1}\right)\end{array}$ & $\begin{array}{c}V_{\text {total }}\left(\mathbf{c m}^{\mathbf{3}}\right. \\
\left.\mathbf{g}^{-1}\right)\end{array}$ & $\begin{array}{c}\boldsymbol{V}_{\text {meso }}\left(\mathbf{c m}^{\mathbf{3}}\right. \\
\left.\mathbf{g}^{-1}\right)\end{array}$ & $\begin{array}{c}\boldsymbol{V}_{\text {micro }}\left(\mathbf{c m}^{\mathbf{3}}\right. \\
\left.\mathbf{g}^{-1}\right)\end{array}$ & $\begin{array}{c}V_{\text {ultra }}\left(\mathbf{c m}^{3}\right. \\
\left.\mathbf{g}^{-1}\right)\end{array}$ & $\begin{array}{c}\mathbf{V}_{\text {super }}\left(\mathbf{c m}^{3}\right. \\
\left.\mathbf{g}^{-1}\right)\end{array}$ & $\mathbf{p H}$ PZC \\
\hline Ch_UC650 & 11 & 530 & 0.30 & 0.10 & 0.20 & 0.00 & 0.20 & 8.9 \\
\hline Ch_UC750 & 12 & 331 & 0.29 & 0.18 & 0.11 & 0.00 & 0.11 & 8.7 \\
\hline Ch_UC900 & 13 & 93 & 0.07 & 0.04 & 0.03 & 0.00 & 0.03 & 8.8 \\
\hline Ch_SC650 & 16 & 494 & 0.35 & 0.17 & 0.18 & 0.00 & 0.18 & 9.3 \\
\hline Ch_SC750 & 17 & 459 & 0.29 & 0.12 & 0.17 & 0.00 & 0.17 & 9.5 \\
\hline Ch_SC900 & 17 & 418 & 0.31 & 0.16 & 0.15 & 0.00 & 0.15 & 9.6 \\
\hline
\end{tabular}

Samples Ch_UC650 and Ch_SC650, chosen as representative of the chars, present similar morphology, composed by irregular and sharp-shaped particles (Figure 2a). Two textures are visible: smooth surfaces, predominantly on the outside of the particles, and a fibrous texture in surfaces located predominantly inside the particles. The co-existence of these textures suggests different degrees of carbonization: the outer surfaces were more efficiently carbonized, presenting a smooth texture, whereas the inner facets maintained the fibrous texture of the original filters. Elements C, O, Ti and K were detected in Ch_UC650 (Figure 2b). Carbon and oxygen originate from the cellulose acetate fibers, and detection of $\mathrm{Ti}$ is attributed to titanium dioxide added to the filters during manufacture. The trace amount of $\mathrm{K}$ can be explained by contamination from tobacco during the preparation of the filters since potassium is added to tobacco as potassium sorbate. The chars prepared from smoked filters present somewhat similar EDS spectra and a some other metals were detected, attributed to additives typically added to tobacco. X-ray diffraction patterns showed that the chars have an amorphous structure, with an extremely wide peak reflection between $2 \theta \approx 5^{\circ}$ and $30^{\circ}$, and confirmed the presence of $\mathrm{TiO}_{2}$ used in the manufacture of the filters (Figure 2c). 
(a)
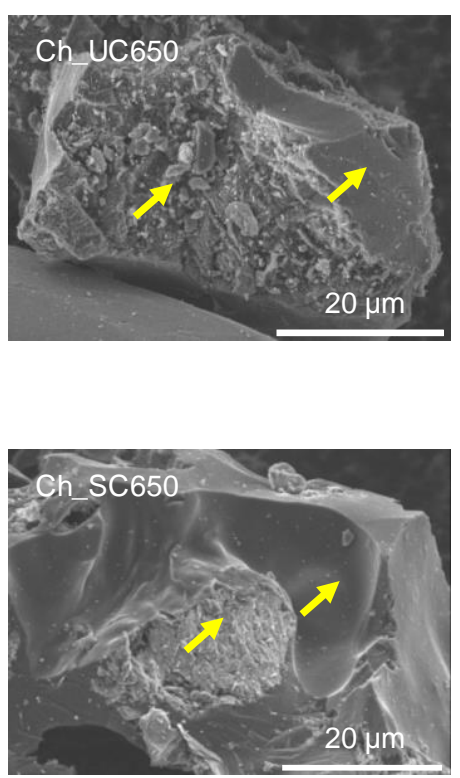

(b)
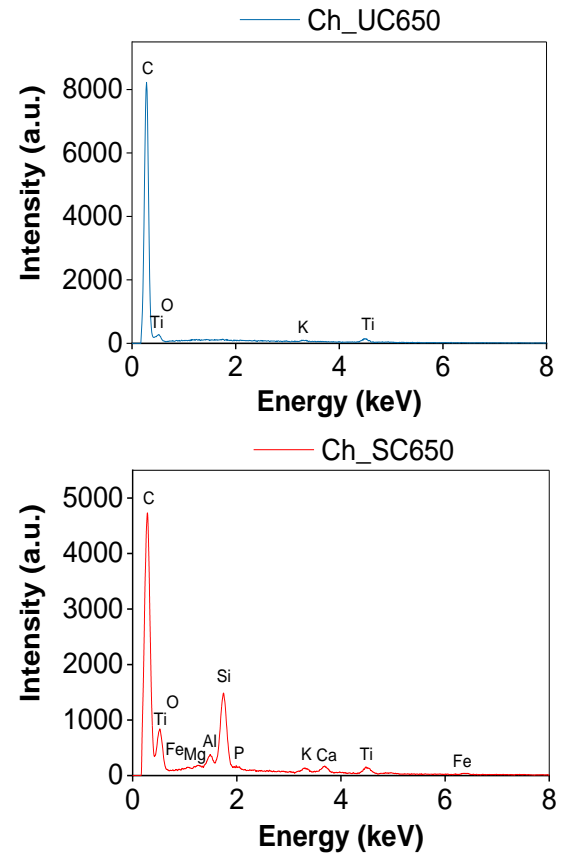

(c)
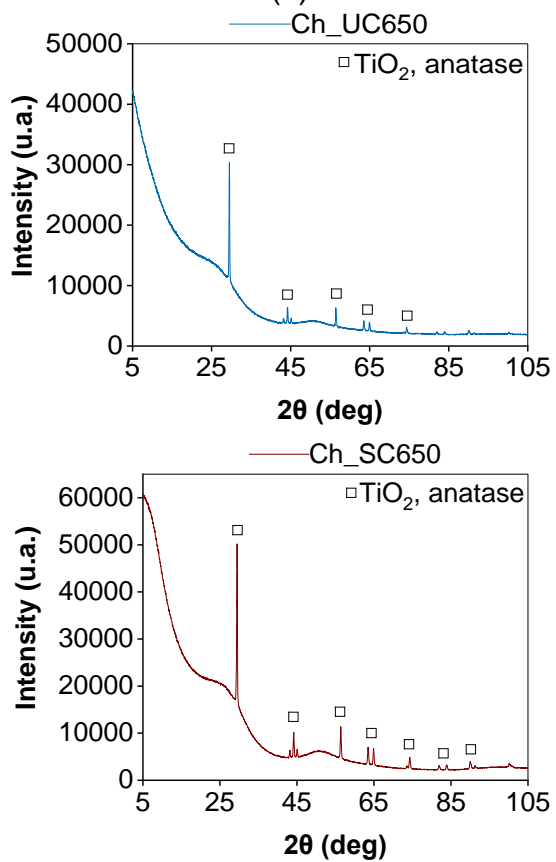

Figure 2 SEM micrographs (a), EDS spectra (b), and X-ray diffractograms (c) of Ch_UC650 and Ch_SC650

\subsection{Membranes}

The procedure adopted for the synthesis of Memb_SF created pores homogeneously distributed throughout the top surface of the membrane (Figure 3). Two types of pores are visible: large pores formed due to acetone evaporation and smaller pores created by $\mathrm{NaCl}$ solid (diameters between 25 and $75 \mu \mathrm{m}$ ). Membrane crosssection confirms the predominance of large evaporation pores close to the top surface of the sample. Using phosphoric acid as catalyst allowed for a controlled development of porosity, and membranes Memb_SF225p and Memb_SF250p present distinct morphological features. A more extensive carbonization occurred at higher temperature leading to larger pores at the top surface of Memb_SF250p. Thus, while Memb_SF225p contains pores diameters mostly between 4 and $6 \mu \mathrm{m}$, Memb_SF250p presents very wide interconnected surface pores, with diameters generally in the range from 60 to $125 \mu \mathrm{m}$.
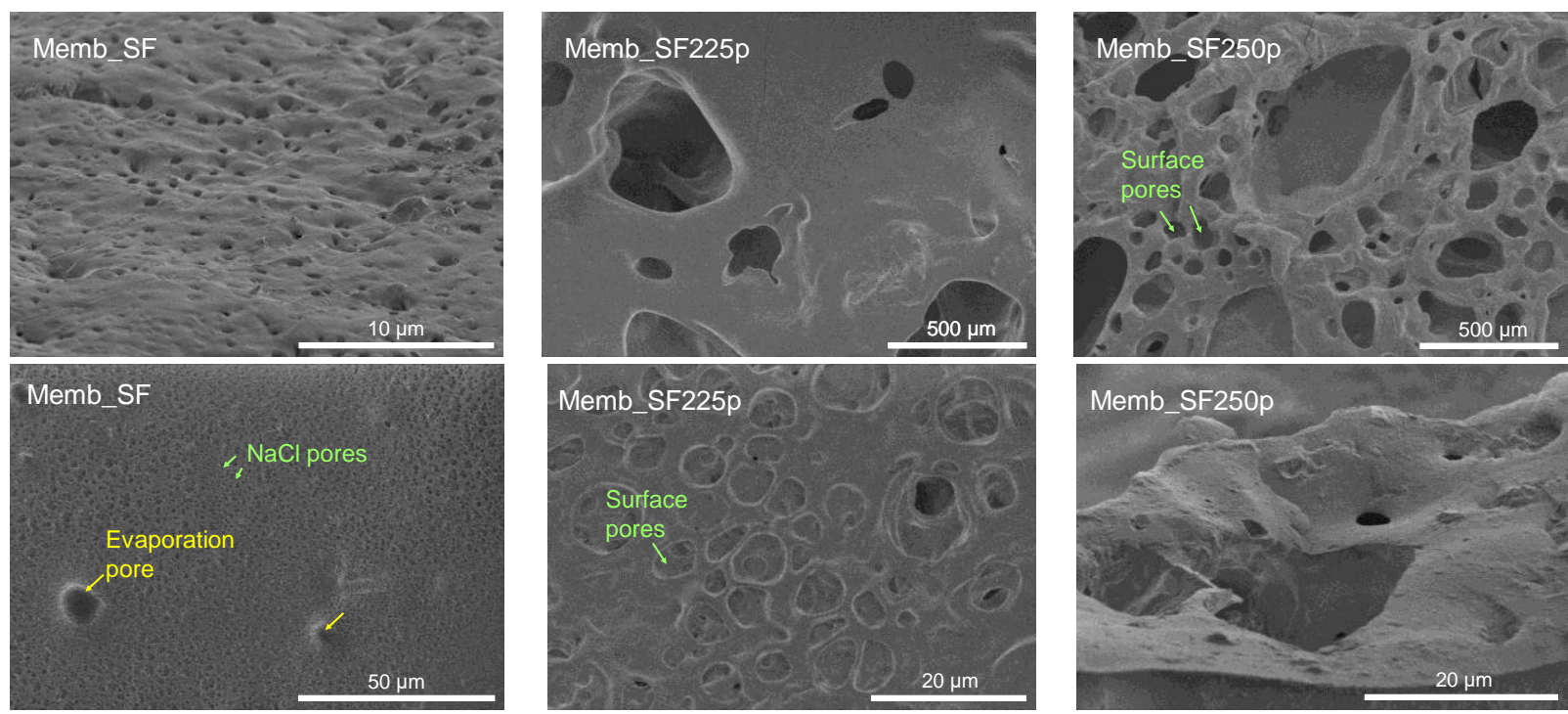

Figure 3 SEM micrographs of Memb_SF, Memb_SF225p and Memb_SF250p 
The un-pyrolysed membranes presented a neutral surface chemistry ( $\mathrm{pH}$ Pzc around 7), which makes sense given that the main component of the filters is cellulose acetate. Acid mediated carbonization led to acidic samples ( $\mathrm{pH}$ PzC values around 3.7), due to the introduction of acidic functionalities during carbonization of the membranes soaked in phosphoric acid.

\subsection{Clofibric acid adsorption}

The adsorption isotherms of the chars (Figure 4) have a profile characteristic of multi-layer adsorption, with more than one saturation plateau. The immersion of the chars caused somewhat similar shifts in solution $\mathrm{pH}$, more pronounced at lower $C_{e}$ values. The joint analysis of the isotherms, final solutions $\mathrm{pH}$ data, and correlation to clofibric acid speciation allowed for a better understanding of the adsorption mechanism [10]. Thus, the isotherms of the chars can be divided into four regions: (1) an initial uptake increase at $C_{\mathrm{e}}$ values around $5 \mathrm{mg} \mathrm{dm}^{-3}$, indicative of cooperative adsorption; (2) a first saturation plateau at solution $\mathrm{pH}$ values above 5, relative to the exclusive adsorption of the deprotonated form of clofibric acid; (3) increase in uptake as the solution $\mathrm{pH}$ approaches value 5 ; (4) $2^{\text {nd }}$ saturation plateau achieved at solution $\mathrm{pH}$ values below 5 ( $C_{\mathrm{e}}$ values higher than $120 \mathrm{mg} \mathrm{g}^{-1}$ ), when both protonated and deprotonated forms of clofibric acid are present in solution. The pHpzc of the chars affected the solution pH data obtained, that is, Ch_SC650 with a pHpzc of 9.3 caused slightly higher deviations in the solutions than Ch_UC650 (pHPzC of 8.9). Nevertheless, these small deviations influenced the adsorption mechanism of clofibric acid, as demonstrated by the different profile of the isotherms of these materials. However, similar final $q_{\mathrm{e}}$ values were reached around $16.5 \mathrm{mg} \mathrm{g}^{-1}$ for both materials, which is in agreement with the similar $V_{\text {micro }}$ present in the chars.
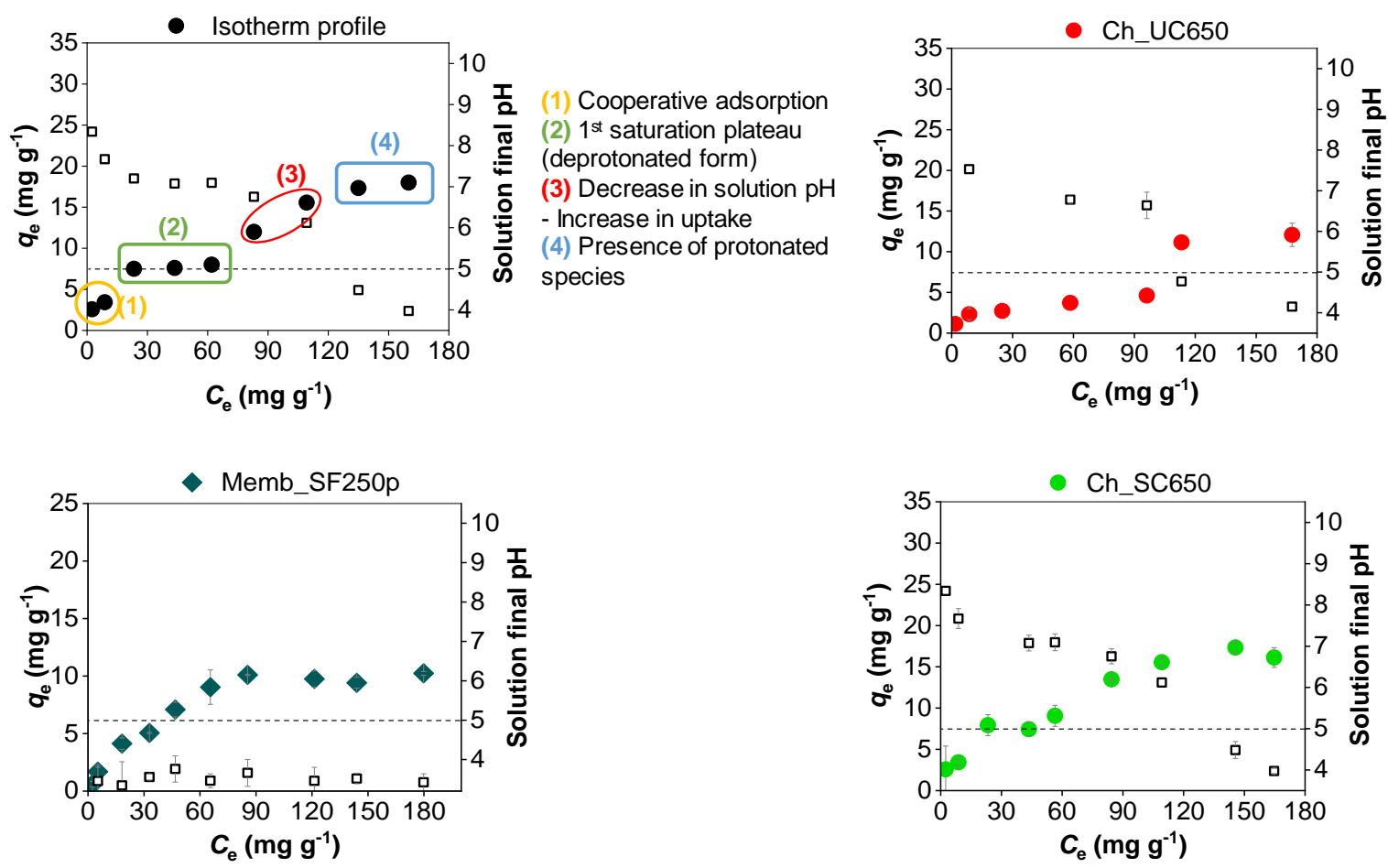

Figure 4 Equilibrium adsorption isotherms profile and data for clofibric adsorption onto the mentioned samples. Solution $\mathrm{pH}$ measurements included

Memb_SF250p, representative of the membranes, caused no solution pH shifts, because its pHpzc is around 3.7, similar to the dissolution $\mathrm{pH}$ of clofibric acid (3.5). Consequently, the adsorption isotherm of this sample is characteristic of monolayer adsorption with a progressive increase in uptake, until saturation was reached at $C_{\mathrm{e}}$ values higher than $90 \mathrm{mg} \mathrm{g}^{-1}$. 


\section{CONCLUSION}

Carbonization of cigarette filters yielded chars with relatively high degrees of porosity. Tobacco contaminants decreased filters sensitivity to carbonization temperature, while allowing for porosity development. The chars are basic in nature and, as expected, $\mathrm{TiO}_{2}$ was detected. Membranes were successfully synthesized and phosphoric acid mediated carbonization allowed for a controlled development of porosity and yielded acidic carbon membranes with wide porosity in the range of the micrometers. The materials immersion in water caused, in general, deviations in the solutions $\mathrm{pH}$ during the adsorption experiments. Increases in $\mathrm{pH}$ had a marked impact in the adsorption mechanism of clofibric acid and in the profile of the adsorption isotherms. Thus, a monolayer characteristic isotherm was obtained for the acidic membrane (no shifts in solution $\mathrm{pH}$ ), and a more pronounced S-type profile was observed for the most basic char Ch_SC650. Still, the final adsorption capacities achieved appear to have been ruled mainly by the microporous volume of the samples.

\section{ACKNOWLEDGEMENTS}

This research was supported by the ERDF projects No. CZ.02.1.01/0.0/0.0/16_019/0000754 and No. CZ.02.1.01/0.0/0.0/17_048/0007323 of the Ministry of Education, Youth and Sports of the Czech Republic, and by the project No. FV20066 from Ministry of Industry and Trade of the Czech Republic. The authors acknowledge the support given by Mgr. Ivo Medřík, Dr. Claudia Aparicio, and Mgr. Lucie Hochvaldová.

\section{REFERENCES}

[1] KADIR, A.A., SARANI, N.A. Cigarette Butts Pollution and Environmental Impact - A Review. Applied Mechanics and Materials. 2015, vol. 773-774, pp. 1106-1110.

[2] TORKASHVAND, J., FARZADKIA, M', SOBHI, H.R., ESRAFILI, A. Littered cigarette butt as a well-known waste: A comprehensive systematic review. Journal of Hazardous Materials. 2020, vol. 383, pp. 1-12.

[3] UBAIDULLAH, M., AHMED, J., AHAMAD, T., SHAIKH, S.F., ALSHEHRI, S.M., AL-ENIZI, A.M. Hydrothermal synthesis of novel nickel oxide@nitrogenous mesoporous carbon nanocomposite using costless smoked cigarette filter for high performance supercapacitor. Materials Letters. 2020, vol. 266, pp. 1-4.

[4] LI, S.H., SHI, C.L., WANG, Y.Z., SUN, X.D., QI, D.W., WU, D., WANG, Y., ZHU, J.H. New efficient selective adsorbent of tobacco specific nitrosamines derived from discarded cigarette filters. Microporous and Mesoporous Materials. 2019, vol. 284, pp. 393-402.

[5] ZHANG, X., XU, J., LV, Z., WANG, Q., GE, H., WANG, X., HONG, B. Preparation and utilization of cigarette filters based activated carbon for removal CIP and SDS from aqueous solutions. Chemical Physical Letters. 2020, vol. 747, pp. 1-9.

[6] ISO 9277. Determination of the specific surface area of solids by gas adsorption - BET method. 2010.

[7] RODRIGUEZ-REINOSO, F., MARTIN-MARTINEZ, J.M. A standard adsorption isotherm for the characterization of activated carbons. Journal of Physical Chemistry - U.S. 1987, vol. 91, pp. 515-516.

[8] MESTRE, A.S., PINTO, M.L., PIRES, J., NOGUEIRA, J.M.F., CARVALHO, A.P. Effect of solution pH on the removal of clofibric acid by cork-based activated carbons. Carbon. 2010, vol. 48, pp. 972-980.

[9] LÉDÉ, J. Cellulose pyrolysis kinetics: An historical review on the existence and role of intermediate active cellulose. Journal of Analytical and Applied Pyrolysis. 2012, vol. 94, pp. 17-32.

[10] DE CAPRARIIS, B.D., BASSANO, C., DEIANA, P., PALMA, V., PETRULLO, A., SCARSELLA, M., DE FILIPPIS, P. Carbon dioxide reforming of tar during biomass gasification. Chemical Engineering Transactions. 2014, vol. 37, pp. 97-102.

[11] GAAN, S., MAUCLAIRE, L., RUPPER, P., SALIMOVA, V., TRAN, T.-T., HEUBERGER. M. Thermal degradation of cellulose acetate in presence of bis-phosphoramidates. Journal of Analytical and Applied Pyrolysis. 2011, vol. 90, pp. 33-41. 